\title{
Recurrent pulmonary thromboembolism during radical cystectomy: A case report
}

\author{
Prasanna Vani Vanamail ${ }^{1}$, Radhika Dash ${ }^{1}$, Kalpana Balakrishnan ${ }^{2}$, Thendral Edwin ${ }^{1}$ \\ From ${ }^{1}$ Assistant Professor, ${ }^{2} \mathrm{HOD}$, Department of Anaesthesiology, Cancer Institute (W.I.A.), Chennai, India
}

\begin{abstract}
Intraoperative incidences of pulmonary embolism (PE) have been reported in orthopedic and neurosurgeries. Here, we present the case of a 69-year-old man who presented with complaints of abdominal pain and hematuria for 2 months. He underwent radical cystectomy for urinary bladder cancer when he suddenly developed severe shock, hypoxia and decrease in lung compliance. We managed hypotension with vasopressors and inotropes guided by cardiac output monitoring. Post-operative CT pulmonary angiography revealed partially occluding thrombi in the left lower lobar pulmonary artery in segmental branches. The patient was started on therapeutic anticoagulation and he recovered subsequently. We commonly encounter thromboembolism in the post-operative period, and clinical presentation of massive occlusive embolus is well recognized. In this case, the presentation was intraoperative and the thrombus was nonmassive, causing only partial obstruction of the pulmonary artery. This atypical presentation of intraoperative non-massive pulmonary thromboembolism needs to be recognized promptly. The use of invasive hemodynamic monitoring and point-of-care echocardiography is vital in the management of intraoperative pulmonary embolism.
\end{abstract}

Key words: Intraoperative, Pulmonary embolism, Radical cystectomy, Thromboembolism

$\mathrm{I}$ ntraoperative incidences of pulmonary embolism (PE) have been reported in orthopedic and neurosurgeries [1,2]. The incidence of venous thromboembolism episodes in cancer patients is $20-30 \%$ [3]. Deep vein thrombosis and PE are the most common perioperative complications following radical cystectomy for urinary bladder cancer [4]. Intraoperative presentation of PE is atypical and often not recognized promptly.

The rationale for reporting this case is to enhance our understanding of non-massive intraoperative pulmonary thromboembolism in terms of its presentation and management. Written informed consent was obtained from the patient for the publication of this manuscript.

\section{CASE REPORT}

A 69-year-old man weighing $67 \mathrm{~kg}$ presented with complaints of abdominal pain and hematuria for 2 months. Abdominal pain was in the lower abdominal region, dull aching, and associated with urinary urgency and hematuria. The patient had well-controlled diabetes mellitus and systemic hypertension for 10 years. No relevant family or psychosocial history was present. The patient had an uneventful

\section{Access this article online}

Received - 15 May 2021

Initial Review - 03 May 2021

Accepted - 14 June 2021

DOI: $10.32677 /$ IJCR.2021.v07.i06.013 previous history of amputation of a toe and transurethral resection of bladder tumor, both under subarachnoid block.

Physical examination was normal. The patient was pale on general examination and pedal edema was absent. The patient's pulse rate was $92 / \mathrm{min}$, blood pressure was $140 / 90 \mathrm{mmHg}$, respiratory rate was $14 / \mathrm{min}$, and saturation of peripheral oxygen $\left(\mathrm{SpO}_{2}\right)$ was $99 \%$. On local examination of the abdomen, mild tenderness over the suprapubic region was noted. No signs of diabetic autonomic neuropathy were present.

Cystoscopy revealed a growth in the urinary bladder, and histopathology of the lesion was suggestive of papillary bladder cancer. The patient was planned for radical cystectomy, bilateral pelvic lymph node dissection, and ileal conduit. The patient was advised preoperative incentive spirometry and a high protein diet.

On the day of surgery, an epidural catheter was placed. General anesthesia (GA) was induced with fentanyl $100 \mathrm{mcg}$ and propofol $100 \mathrm{mg}$. Atracurium $35 \mathrm{mg}$ was given for neuromuscular block, and the trachea was intubated. Approximately 45 min post-induction, the patient had sudden severe hypotension, desaturation, fall in end-tidal carbon-di-oxide $\left(\mathrm{EtCO}_{2}\right)$, and bilateral bronchospasm. The event coincided with bladder manipulation. Intravenous adrenaline $100 \mathrm{mcg}$, hydrocortisone $100 \mathrm{mg}$, and fluid bolus were administered. Noradrenaline infusion was commenced to maintain hemodynamics. Due to persistent hypotension, surgery

Correspondence to: Prasanna Vani Vanamail, Room No. 10, Surgical Oncology Block, Cancer Institute (WIA), 38 Sardar Patel Road, Adyar, Chennai, Tamil Nadu, India. E-mail: prasna.vani@gmail.com

(C) 2021 Creative Commons Attribution-NonCommercial 4.0 International License (CC BY-NC-ND 4.0). 
was abandoned and the patient was ventilated till hemodynamic stability was achieved. Shock resolution occurred within $6 \mathrm{~h}$ postoperatively. The trachea was extubated the following day.

Post-operative troponin I was negative, D-Dimer was elevated at $8.36 \mathrm{mcg} / \mathrm{ml}$ (reference values $<0.5 \mathrm{mcg} / \mathrm{ml}$ ), and 12-lead electrocardiogram (ECG) showed qs pattern with $\mathrm{T}$ wave inversion in Lead III and occasional ventricular premature complexes. Bedside echocardiography showed normal left ventricular function and right ventricular free wall hypokinesia. A tentative diagnosis of PE was made. Bilateral lower limb and pelvic venous scans revealed no deep vein thrombosis.

The patient developed acute kidney injury on post-operative day 1 , for which he underwent renal replacement therapy. The patient was counseled about the probability of pulmonary embolism as a differential diagnosis for the above sequence of events and the risks of contrast exposure on his recovering renal function. He refused CT pulmonary angiography. He recovered subsequently and was discharged on therapeutic anticoagulation with a plan to be reviewed after 6 weeks for the same surgery.

After 6 weeks, when the patient returned, his creatinine was $1.5 \mathrm{mg} \cdot \mathrm{dL}^{-1}$. Physical examination was unremarkable. Dobutamine stress echocardiogram was done considering the previous hemodynamic instability, and it was negative for inducible ischemia. On the day of surgery, an epidural catheter was placed in T10-T11 space. GA was induced with fentanyl $100 \mathrm{mcg}$ and etomidate $18 \mathrm{mg}$ and propofol $50 \mathrm{mg}$ in titrated doses. Neuromuscular block was achieved with cisatracurium $10 \mathrm{mg}$. The trachea was intubated, and anesthesia was maintained with oxygen/air/desflurane at $0.8-1$ minimum alveolar concentration. Neuromuscular block was maintained with cisatracurium $2 \mathrm{mg}$ boluses. A central venous catheter and the arterial line were secured for continuous intra-arterial blood pressure monitoring. Epidural infusion of ropivacaine $0.2 \%$ with fentanyl $2 \mathrm{mcg} / \mathrm{ml}$ was started at $4 \mathrm{ml} / \mathrm{h}$. Ninety minutes after anesthesia induction and $30 \mathrm{~min}$ after skin incision, sudden hypotension to blood pressure (BP) $62 / 40 \mathrm{mmHg}$ was noted. This was coincident with bladder manipulation. Heart rate was $90 / \mathrm{min}$ at that time with end-tidal carbon dioxide $\left(\mathrm{EtCO}_{2}\right)$ of $19 \mathrm{mmHg}$, and $\mathrm{SpO}_{2}$ of 93\%. Ephedrine two $6 \mathrm{mg}$ boluses were given. Inspired oxygen concentration was increased to $100 \%$. Arterial blood gas analysis showed a $\mathrm{pH} 7.26$, partial pressure of carbon dioxide $\left(\mathrm{PaCO}_{2}\right)$ $46 \mathrm{mmHg}$, bicarbonate 20 meq. $\mathrm{L}^{-1}$, and partial pressure of oxygen $97 \mathrm{mmHg}$. Auscultation revealed bilateral normal breath sounds. Point-of-care echocardiography revealed normal left ventricular systolic function with mild dilation of the right atrium (RA) and right ventricle (RV). As hypotension persisted, adrenaline $100 \mathrm{mcg}$ intravenous bolus was given. Within $2 \mathrm{~min}$, BP improved to $128 / 56, \mathrm{EtCO}_{2} 35 \mathrm{mmHg}, \mathrm{SpO}_{2} 95 \%$. Five minutes later, $\mathrm{BP}$ came down to $82 / 50$ with gradually decreasing with $\mathrm{SpO}_{2}$ to $95 \%$ and $\mathrm{EtCO}_{2}$ to 31. Noradrenaline infusion was started and titrated. A decrease in lung compliance from 33 to $19 \mathrm{ml} / \mathrm{cm} \mathrm{H}_{2} \mathrm{O}$ was also seen during this event, accompanied by increased driving pressures to 27 from $14 \mathrm{~cm} \mathrm{H}_{2} \mathrm{O}$. Hydrocortisone $100 \mathrm{mg}$ was given. FloTrac (Edwards Lifesciences, Irvine, CA, USA) cardiac output monitoring was commenced. Systemic vascular resistance (SVR) was low at 1063 dynes-sec- $\mathrm{cm}^{-5}$, stroke volume was $43 \mathrm{ml}$, and pulse pressure variation was 18 . Fluids were given titrated to pulse pressure variation. ECG was normal except for sinus tachycardia. Mean arterial pressure (MAP) was maintained above $65 \mathrm{mmHg}$ with noradrenaline $0.5 \mathrm{mcg} / \mathrm{kg} / \mathrm{min}$. Given low stroke volume, dobutamine infusion was started and titrated to MAP $>70$. SVR continued to be low, and vasopressin infusion was started and titrated up to 1.8 units/h. Radical cystectomy and ileal conduit were completed. At the end of the surgery, the patient was not reversed and electively ventilated because of the high vasopressor requirement. The patient was on noradrenaline $0.5 \mathrm{mcg} / \mathrm{kg} / \mathrm{min}$, dobutamine $12 \mathrm{mcg} / \mathrm{kg} / \mathrm{min}$, and vasopressin 1.8 units $/ \mathrm{h}$ to maintain MAP $>70 \mathrm{mmHg}$. The patient was ventilated in pressure control (PC) mode with a $\mathrm{PC}$ of 15 , positive endexpiratory pressure of $10 \mathrm{~cm} \mathrm{H}_{2} \mathrm{O}$, and $\mathrm{FiO}_{2} 60 \%$.

Bedsides, echocardiography done postoperatively showed normal left ventricular function, right ventricular free wall hypokinesia (McConnell sign) with mild RA, RV dilation, and mild-to-moderate tricuspid regurgitation, inferior vena cava diameter was $1.8 \mathrm{~cm}$ with $<20 \%$ respiratory variation. Lactate was $1.09 \mathrm{mmol} . \mathrm{L}^{-1}$ and the central venous pressure was $12 \mathrm{~cm}$ water. Shock resolution occurred within $10 \mathrm{~h}$ postoperatively. Therapeutic anticoagulation with dalteparin was started. Doppler study of both the lower limb vessels again did not show any evidence of deep vein thrombosis. D-dimer was $1.9 \mathrm{mcg} / \mathrm{ml}$. CT pulmonary angiogram was done after hemodynamic stability was achieved. It showed a partially occluding thrombus in segmental branches of the left lower lobar pulmonary artery, a right lobar consolidation, and bilateral subsegmental atelectasis (Fig. 1a and b).

The patient's trachea was extubated on the $1^{\text {st }}$ post-operative day and was supported with intermittent non-invasive ventilation for further 2 days. His intensive care unit stay was punctuated with two episodes of non-sustained atrial fibrillation controlled with beta-blockers and transient acute kidney injury not requiring renal replacement therapy. The patient was discharged on a post-operative day 14 on therapeutic anticoagulation and betablocker therapy in addition to his existing medications. His histopathology report revealed non-invasive papillary urothelial carcinoma (low grade). The patient and his family were satisfied with the perioperative care provided.

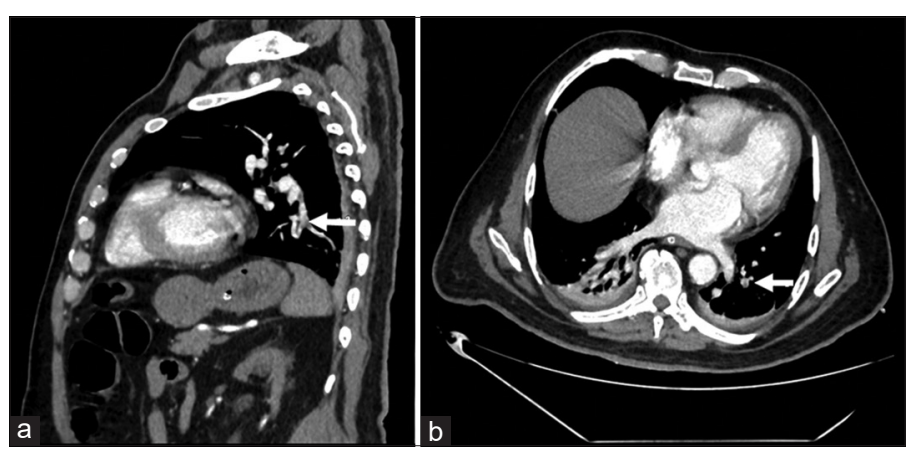

Figure 1: CT pulmonary angiogram showing filling defects (arrow) with distal flow of contrast suggestive of partial occlusion of the left lower lobar pulmonary artery in (a) sagittal image and (b) axial image 


\section{DISCUSSION}

Pulmonary thromboembolism is a diagnosis of exclusion, with dyspnea being its most predominant symptom [5]. GA masks the symptoms of PE. Intraoperative presentation of PE mimics other intraoperative scenarios such as anaphylactic or hemorrhagic shock and acute coronary syndromes $[6,7]$.

The separation phenomenon of increasing $\mathrm{PaCO}_{2}(46 \mathrm{~mm})$ and decreasing $\mathrm{EtCO}_{2}(19 \mathrm{~mm})$ along with invasive cardiac monitoring and point-of-care ultrasound assisted the diagnosis and management [1]. Massive PE has been reported earlier, where the circulatory changes were due to obstruction in pulmonary vessels. In our patient, it was probably a shower of small emboli as the echocardiographic changes were not as dramatic. Systemic hypotensive reaction to massive $\mathrm{PE}$ is due to a decreased cardiac output after mechanical obstruction. However, severe hypotensive response in submassive or segmental embolism is best explained based on a vasomotor reflex producing a decrease in systemic arterial resistance [8]. Age-adjusted D-dimer values have level IIa evidence for PE, and our patient fell within these criteria [8].

The clinical features could be due to the release of humoral factors, such as serotonin from platelets, histamine from tissue, endothelin, prostaglandin $\mathrm{F} 2 \alpha$, and prostacyclin from the endothelium [9]. These act as pulmonary vasoconstrictors, systemic vasodilators, and cardiac depressants [10]. As blood flow is shunted away from obstructed branches of the pulmonary artery, there is over perfusion of the rest of the lung, resulting in edema, loss of surfactant, atelectasis, and reduced lung compliance [11]. Complete obstruction of pulmonary artery increases anatomical dead space and elevates $\mathrm{PaCO}_{2}$ [12]. In partial obstruction, there is increased physiological dead space due to increased shunt fraction [13]. Our patient presented with low SVR, increased shunt, and reduced lung compliance.

Vigilance is needed to diagnose non-massive PE. A modest fluid challenge can increase cardiac index and norepinephrine and dobutamine increase right ventricular function in acute PE [14]. There is emerging evidence for the role of pulmonary vasodilators in PE [9]. Intraoperative massive PE, possibly from tumor thrombi, has also been reported in a patient planned for craniotomy for astrocytoma before the start of surgery [15]. The patient was managed with hemodynamic resuscitation, inferior vena cava filter placement, and anticoagulation. Intraoperative presentation of non-massive PE has not been described before.

\section{CONCLUSION}

In any sudden hemodynamic collapse in a perioperative patient, pulmonary thromboembolism should be considered in the differential diagnosis, especially in a cancer patient. This report demonstrates the importance of recognizing acute nonmassive thromboembolism with a predominance of vasomotor symptoms. Timely diagnosis and management, aided by point-of-care ultrasonography and invasive cardiac output monitoring, will improve the outcome of this life-threatening complication.

\section{REFERENCES}

1. Mao Y, Wen S, Chen G, Zhang W, Ai Y, Yuan J. Management of intraoperative acute pulmonary embolism during general anesthesia: A case report. BMC Anesthesiol 2017;17:67.

2. Aiping Y, Shuangyin Z, Yanhong X, Rongzhi Z. Management of intraoperative acute pulmonary embolism in a patient with subarachnoid haemorrhage undergoing femoral fracture repair. J Int Med Res 2019;47:5307-11.

3. Gussoni G, Frasson S, La Regina M, Di Micco P, Monreal M. Threemonth mortality rate and clinical predictors in patients with venous thromboembolism and cancer. Findings from the RIETE registry. Thromb Res 2013;131:24-30.

4. Novotny V, Hakenberg OW, Wiessner D, Heberling U, Litz RJ, Oehlschlaeger $\mathrm{S}$, et al. Perioperative complications of radical cystectomy in a contemporary series. Eur Urol 2007;51:397-402.

5. Stein PD, Beemath A, Matta F, Weg JG, Yusen RD, Hales CA, et al. Clinical characteristics of patients with acute pulmonary embolism: Data from PIOPED II. Am J Med 2007;120:871-9.

6. Liu CC, Hung TC, Hou CJ, Tsai CH. Acute pulmonary embolism mimics acute coronary syndrome in older patient. Int J Gerontol 2009;3:251-5.

7. Morrone D, Morone V. Acute pulmonary embolism: Focus on the clinical picture. Korean Circ J 2018;48:365-81.

8. Konstantinides SV, Meyer G, Bueno H, Geersing GJ, Harjola VP, Huisman MV, et al. 2019 ESC Guidelines for the diagnosis and management of acute pulmonary embolism developed in collaboration with the European respiratory society (ERS). Eur Heart J 2020;41:543-603.

9. Lyhne MD, Kline JA, Nielsen-Kudsk JE, Andersen A. Pulmonary vasodilation in acute pulmonary embolism a systematic review. Pulm Circ 2020;10:2045894019899775.

10. Stratmann G, Gregory GA. Neurogenic and humoral vasoconstriction in acute pulmonary thromboembolism. Anesth Analg 2003;97:341-54.

11. Desciak MC, Martin DE. Perioperative pulmonary embolism: Diagnosis and anesthetic management. J Clin Anesth 2011;23:153-65.

12. Sekhri V, Mehta N, Rawat N, Lehrman SG, Aronow WS. Management of massive and nonmassive pulmonary embolism. Arch Med Sci 2012; 8:957-69.

13. Goldhaber SZ, Elliott CG. Acute pulmonary embolism: Part I: Epidemiology, pathophysiology, and diagnosis. Circulation 2003;108):2726-9.

14. Yamamoto T. Management of patients with high-risk pulmonary embolism: A narrative review. J Intensive Care 2018;6:16.

15. Khraise WN, Allouh MZ, Hiasat MY, Said RS. Successful management of intraoperative acute bilateral pulmonary embolism in a high grade astrocytoma patient. Am J Case Rep 2016;17:632-6.

Funding: None; Conflicts of Interest: None Stated.

How to cite this article: Vanamail PV, Dash R, Balakrishnan K, Edwin T. Recurrent pulmonary thromboembolism during radical cystectomy: A case report. Indian J Case Reports. 2021;7(6):260-262. 